\title{
Threshold effects of glucose transporter-4 (GLUT4) deficiency on cardiac glucose uptake and development of hypertrophy
}

\author{
S J Kaczmarczyk, S Andrikopoulos, J Favaloro, A A Domenighetti ${ }^{1}$, A Dunn ${ }^{2}$, \\ M Ernst ${ }^{2}$, D Grail ${ }^{2}$, M Fodero-Tavoletti, C E Huggins ${ }^{1}$, L M Delbridge ${ }^{1}$, J D Zajac ${ }^{3}$ \\ and $\mathbf{J}$ Proietto
}

\author{
University of Melbourne, Department of Medicine, The Royal Melbourne Hospital, Parkville, VIC 3050, Australia \\ ${ }^{1}$ Department of Physiology, University of Melbourne, Parkville, VIC 3050, Australia \\ ${ }^{2}$ Tumour Biology Branch, Ludwig Institute for Cancer Research, The Royal Melbourne Hospital, Parkville, VIC 3050, Australia \\ ${ }^{3}$ University of Melbourne, Department of Medicine, Austin and Repatriation Medical Centre, Heidelberg, VIC 3084, Australia
}

(Requests for offprints should be addressed to J D Zajac; Email j.zajac@ unimelb.edu.au)

\begin{abstract}
The aim of this study was to investigate the metabolic and structural consequences of a decrease in glucose transporter-4 (GLUT4) levels on the heart. The CreLoxP system was utilised to delete GLUT4 in muscle tissue including heart. The presence of the PGK-neoR cassette in the GLUT4-Lox mice resulted in reduced expression in all tissues to levels $15-30 \%$ of wild-type control mice. In mice expressing Cre recombinase, there was a further reduction of GLUT4 in cardiac tissue to almost undetectable levels. Cardiac glucose uptake was measured basally and during a euglycaemic/hyperinsulinaemic clamp using 2-deoxy-[1- $\left.{ }^{14} \mathrm{C}\right]$ glucose. Insulin-stimulated glucose uptake was normal in hearts expressing $15 \%$ of normal GLUT4 levels but markedly reduced in mice with more profound reduction in GLUT4. Cardiac enlargement occurred only when GLUT4 levels were less than $5 \%$ of normal values. In heart there is a threshold level of GLUT4 above which insulin-stimulated glucose uptake is maintained. As little as $5 \%$ of normal GLUT4 levels expressed in heart is sufficient to prevent the development of cardiac hypertrophy.
\end{abstract} Journal of Molecular Endocrinology (2003) 31, 449-459

\section{Introduction}

Diabetes is associated with cardiac pathology in the absence of coronary artery disease or high blood pressure (Nielsen et al. 1997, Hirayama et al. 2000) and diabetic patients have poorer outcomes following myocardial infarction (Sprafka et al. 1991). An autopsy study found that cardiac weight was significantly greater in patients with both hypertension and diabetes compared with patients with hypertension or diabetes alone (van Hoeven \& Factor 1990).

The cause of this diabetic cardiac pathology remains unclear; however, it is known that manipulation of nutrient supply to the heart results in changes in cardiac morphology. Rats in which mitochondrial free fatty acid oxidation is inhibited with the carnitine palmitoyl transferase- 1 inhibitor, 2-tetradecylglycidic acid, develop cardiac hypertrophy in the absence of changes in blood pressure (Litwin et al. 1990b, Bressler \& Goldman 1993). Although the heart preferentially metabolises fat, human studies have shown that glucose metabolism becomes important when there are high energy needs such as with exercise (Gertz et al. 1988). Cardiac glucose uptake is mediated by the glucose transporters GLUT1 and GLUT4 (Kraegen et al. 1993). Both insulin and exercise increase cardiac glucose uptake by translocating GLUT4 to the cell surface (Slot et al. 1991). Streptozotocin-induced diabetes results in a dilated cardiomyopathy that is reversed by insulin (Litwin et al. 1990a) and is 
associated with a 50\% decrease in the insulinresponsive glucose transporter GLUT4 protein and mRNA, accompanied by a $53 \%$ reduction in glucose transport into cardiac sarcolemmal vesicles (Garvey et al. 1993).

To investigate the impact of reduced GLUT4mediated glucose uptake, several animal models have been produced in which GLUT4 expression is genetically suppressed. Whole-body global deletion of GLUT4 resulted in a 2.5-fold increase in heart/body weight ratio with myocyte hypertrophy and interstitial fibrosis (Katz et al. 1995, Stenbit et al. 2000). These animals exhibited marked elevation of plasma insulin and disturbances in plasma glucose regulation. However, cardiac glucose uptake was not diminished, apparently due to a coincident upregulation of the GLUT1 transporter. In cardiac-specific GLUT4 knockout mice, cardiac hypertrophy was more modest (heart weight/body weight ratio increased 1.43 -fold in males and 1.25-fold in female mice compared with wild-type mice) and there was no evidence of fibrosis (Abel et al. 1999). In this model, plasma glucose and insulin levels were found to be normal.

To further investigate the cardiac effects of impaired glucose uptake, our goal was to generate a new experimental model in which disruption of the GLUT4 transporter in both skeletal and cardiac muscle was achieved. We produced mice with deletion of GLUT4 using the CreLoxP system, selecting the muscle-specific $\alpha$-actin gene promoter to drive the GLUT4 ablation. In what is now a well-described occurrence (Meyers et al. 1998, Nagy 2000, $\mathrm{Xu}$ et al. 2001), the presence of the PGK-neoR cassette in the GLUT4-Lox gene caused the 'knockdown' phenomenon, reducing GLUT4 gene transcription in many tissues of the $\mathrm{Lox}^{+/+}$mice, producing animals with more widespread, but less marked reduction in GLUT4 levels. The presence of Gre recombinase in GLUT4-Lox ${ }^{+/+} \mathrm{Cre}^{+/-}$mice further reduced GLUT4 in the heart to an almost undetectable level. Thus, the use of the CreLoxP system in this instance has produced two phenotypes which may be contrasted with the wild-type - a generalised suppression of GLUT4 expression $\left(\operatorname{Lox}^{+/+}\right.$) upon which may be superimposed a cardiac-specific virtual ablation of GLUT4 $\left(\mathrm{Lox}^{+/+} \mathrm{Cre}^{+/-}\right)$. We report here threshold effects of GLUT4 levels on in vivo glucose uptake and on the development of cardiac hypertrophy.

\section{Materials and methods}

\section{Construction of GLUT4-Lox transgenic mice}

The glucose transporter gene GLUT4 was cloned from a $129 \mathrm{SvJ}$ mouse genomic library constructed in the FixII phage vector (Stratagene, La Jolla, CA, USA) by screening with two oligonucleotide probes corresponding to either end of the GLUT4 gene. The full length GLUT4 gene including the promoter was sub-cloned into the BamHI site of pSP72 (Promega) (pSP72-G4) and characterised by restriction enzyme digestion, Southern blotting and sequencing. Double-stranded oligonucleotides encoding LoxP sites flanked by restriction enzyme sites were assembled after the synthesis of single-stranded oligonucleotides (Geneworks, Adelaide, SA, Australia). The Lox-I oligonucleotide was inserted into the AvaI restriction site in the intron between exons 6 and 7, and Lox-II was inserted into the $3^{\prime}$ non-coding region (Acc I) of exon 11 . The gene for neomycin resistance (neoR) with a PGK promoter was inserted $5^{\prime}$ to the Lox-II site. The resulting targeting vector $(\mathrm{pG} 4 \cdot 4)$ was sequenced to confirm the correct orientation of the LoxP sites and that the GLUT4 gene had been reconstituted. This vector was designed so that after homologous recombination and gene replacement, Cre-recombinase would remove the $5 \mathrm{~kb}$ region between the two LoxP sites, which includes exons 7-11 together with the PGK-neoR selection cassette (Fig. 1A).

Introduction of the modified GLUT4 gene into embryonal stem (ES) cells, and the production of mice incorporating this modification, was carried out using standard homologous recombination methodology (Hogan et al. 1986, Lieschke et al. 1994). Briefly, ES.W9.5 cells (derived from 129 SvJ mice) growing on a primary embryonal fibroblast feeder layer, were transfected with the targeting vector pG4.4 by electroporation at $270 \mathrm{~V}, 500 \mathrm{~F}$. One thousand two hundred neomycin-resistant colonies were screened using a locus-specific PGR primer set designed to identify targeted integration of the vector (Fig. 1A). Another set of primers in the unmodified portion of the GLUT4 gene was used as control. Eight independent ES cell colonies containing the GLUT4-Lox transgene inserted at the homologous site were identified by PCR and confirmed using Southern analysis (strategy described in legend to Fig. 1A). ES cells with the GLUT4-Lox modified gene were injected into 

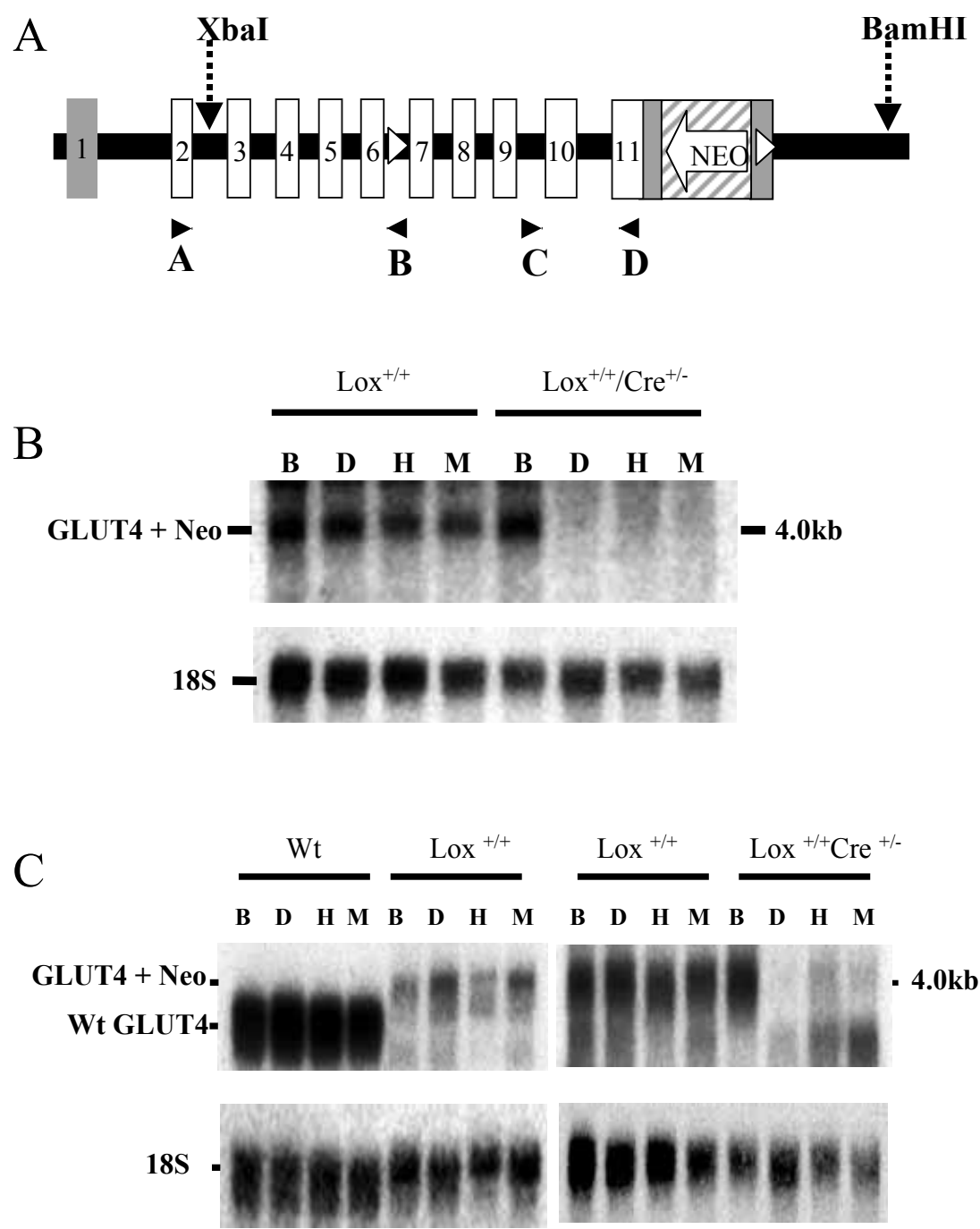

Figure 1 (A) The GLUT4 gene, showing coding exons $(\square)$ and Lox sites $(\triangleright)$. Homologous recombination of the targeting fragment Xbal-BamHI into ES cell DNA was detected by PCR using oligonucleotides $\mathrm{A}$ and $\mathrm{B}$.

Oligonucleotides C and D amplify the endogenous GLUT4 gene. Correct homologous recombination was confirmed by Southern blotting of ES cell genomic DNA digested with BamHI and probed with Neo DNA visualising a $12 \mathrm{~kb}$ band. The length of homologous DNA flanking the LoxP sites was $1 \mathrm{~kb}$ at the $5^{\prime}$-end and $1.2 \mathrm{~kb}$ at the $3^{\prime}$-end of the targeting fragment. (B) Northern analysis of tissues from Lox ${ }^{+/+}$and $\mathrm{Lox}^{+/+} \mathrm{Cre}^{+/-}$mice. RNA (10 $\mu \mathrm{g}$ per gel track) was transferred to Hybond $\mathrm{N}+$ membrane (Amersham) and probed with the Neo-coding region. In $\mathrm{Lox}^{+/+}$samples, the probe binds to a band the same size as the one binding to the GLUT4 probe. This is consistent with production of a transcript from the targeted allele, extending through the GLUT4 mRNA and continuing in an antisense direction through the Neo gene. As anticipated, this transcript is not present in $\mathrm{Lox}^{+/+} \mathrm{Cre}^{+/-}$mice in the tissues expressing Cre recombinase under the $\alpha$-actin promoter, i.e. in diaphragm, heart and muscle. The Northern was re-probed with an $18 \mathrm{~S}$ probe to show even RNA loading. B, brown adipose tissue; D, diaphragm; H, heart; M, muscle. (C) Northern blot probed with a cDNA probe spanning exons 3-11 of the GLUT4-coding region. The right-hand panel, with the Lox ${ }^{+/+}$ and $\mathrm{Lox}^{+/+} \mathrm{Cre}^{+/-}$samples, needed to be exposed 10 times longer than the wild-type $(\mathrm{Wt})$ samples to show bands of an equivalent intensity to the Wt. The $4.0 \mathrm{~kb}$ GLUT4+Neo transcript was markedly reduced in the tissues in which Cre activity was present. The filters were re-hybridised with the control $18 \mathrm{~S}$ probe. B, brown adipose tissue; $D$, diaphragm; $H$, heart; $M$, muscle. 
blastocycts from C57BL/ $6 \times \mathrm{BA}$ mice. Chimeric pups were crossed with $\mathrm{C} 57 \mathrm{BL} / 6$ mice and offspring screened as described above for the ES cell colonies to identify germline transmission of the GLUT4-Lox modified gene. Breeding heterozygous GLUT4-Lox ${ }^{+/-}$produced homozygous $\left(\right.$ Lox $\left.^{+/+}\right)$animals.

\section{Construction of $\alpha$-actin-CRE expression vector and transgenic mice}

The pBS-185 plasmid (Du Pont, Wilmington, DE, USA) was linearised with XhoI and the $2 \cdot 3 \mathrm{~kb}$ HindIII fragment containing the human skeletal muscle-specific $\alpha$-actin gene promoter from pHSA2000 CAT (Muscat \& Kedes 1987) inserted to drive Gre recombinase expression. The $\alpha$-actin skeletal muscle promoter directs expression at the end of gestation and postnatally, specifically in skeletal and cardiac muscle (Brennan \& Hardeman 1993, Miniou et al. 1999). The Cre transgene was introduced into fertilised oocytes from C57BL6 $\times$ GBA mice by pronuclear injection. Three foster mothers were implanted with oocytes containing the injected transgene, resulting in the birth of 29 live pups.

\section{Production and maintenance of GLUT4-Lox ${ }^{+/+} \mathrm{Cre}^{+/-}$mice}

$\mathrm{Cre}^{+/-}$mice were mated with homozygous GLUT4-Lox $^{+/+}$mice. The resulting doubleheterozygous GLUT4-Lox ${ }^{+/-} \mathrm{Cre}^{+/-}$animals were mated with GLUT4-Lox ${ }^{+/+}$mice and the GLUT4$\mathrm{Lox}^{+/+} \mathrm{Cre}^{+/-}$mice identified by PCR and Southern blotting. The colony was maintained by breeding GLUT4-Lox ${ }^{+/+} \mathrm{Cre}^{+/-}$with GLUT4$\mathrm{Lox}^{+/+}$and identifying the $\mathrm{Cre}^{+/-}$mice by PCR . The genetic background of the GLUT4-Lox ${ }^{+/+}$ $\mathrm{Cre}^{+{ }^{+}-}$mice is $56 \cdot 25 \% \mathrm{C} 57 \mathrm{BL} / 6,37 \cdot 5 \% 129 \mathrm{~Sv}$ and $6 \cdot 25 \%$ CBA. The wild-type controls are $100 \%$ C57BL/6.

Mice were housed in The University of Melbourne Department of Medicine, Royal Melbourne Hospital, and maintained on a $12 \mathrm{~h}$ light: $12 \mathrm{~h}$ darkness cycle with lights on at 0600 until $1800 \mathrm{~h}$. Room temperature was kept constant at $20^{\circ} \mathrm{C}$. Animals were fed standard mouse chow consisting of $20 \%$ protein, $75 \cdot 5 \%$ carbohydrate and $4 \cdot 5 \%$ fat. All animals had free access to drinking water. The investigation conforms with the Guide for the Care and Use of Laboratory Animals published by the US National Institutes of Health (NIH publication No. 85-23, revised 1996) and was approved by the Royal Melbourne Hospital animal ethics committee.

\section{Metabolic studies}

Plasma glucose concentration ( $\mathrm{mmol} / \mathrm{l})$ was determined on a $25 \mu$ l aliquot of plasma using a glucose oxidase assay in an automated glucose analyser (YSI, Inc., Yellow Springs, OH, USA). Plasma insulin concentration $(\mu \mathrm{U} / \mathrm{ml})$ was determined using a commercially available RIA kit (Pharmacia). Mice were fasted overnight and anaesthetised with $60 \mathrm{mg} / \mathrm{kg}$ pentobarbital sodium. Catheters were placed in the right jugular vein for infusion and the left carotid artery for blood sampling. A tracheotomy was performed to prevent upper airways obstruction. Temperature was monitored with a rectal probe and maintained at $37^{\circ} \mathrm{C}$ using a heating lamp. Whole-body glucose turnover and cardiac, skeletal muscle and fat glucose uptake were measured fasting and during a hyperinsulinaemic euglycaemic clamp in anaesthetised mice using $\left[6-{ }^{3} \mathrm{H}\right]$ glucose and 2-deoxy- $\left[1-{ }^{14} \mathrm{C}\right]$ glucose respectively as previously described (Veroni et al. 1991).

\section{Blood pressure measurements}

Mice were anaesthetised by i.p. injection containing ketamine $(100 \mathrm{mg} / \mathrm{kg})$, xylazine $(2.5 \mathrm{mg} / \mathrm{kg})$ and heparin $(5000 \mathrm{IU} / \mathrm{kg})$. All surgical procedures were performed under a dissecting microscope. An incision was made from the mandible to the sternum, followed by blunt dissection of the thyroid. The carotid artery was exposed and dissected away from both the internal jugular vein and the vagus nerve. The rostral end was ligated using a 5-0 suture and the caudal end was temporarily blocked using an aneurysm clip. The carotid artery was punctured using a $26 \mathrm{G}$ needle, followed by insertion of a polyethylene catheter $(\mathrm{PE}$ 10), attached to a pressure transducer (MLT 844; ADInstruments, Castle Hill, New South Wales, Australia). Two sutures were placed around the artery to secure the catheter, and the aneurysm clip was removed (Nemoto et al. 2003). Blood pressure was recorded using a MacLab data acquisition system and Chart (v4.2) analysis software (ADInstruments). 


\section{Molecular studies}

Western analysis was performed using standard methods. A rabbit polyclonal antibody specific for GLUT4 (R1159) (Kelada et al. 1992) and a GLUT1 antibody purchased from Santa Cruz Biotechnology (Santa Cruz, CA, USA) were used. RNA and DNA preparations, and Northern and Southern blotting were performed using standard molecular biological techniques (Sambrook et al. 1989; Fig. 1).

\section{Preparation of cardiac tissue for histology}

Hearts from 14-week-old male mice were excised under anaesthesia (pentobarbitone sodium, $100 \mathrm{mg} / \mathrm{kg}$, i.p.), washed in $0.9 \%$ saline solution and weighed. The cardiac weight index $(\mathrm{CWI})$ was calculated for all hearts by normalising heart weight to body weight $(\mathrm{mg} / \mathrm{g})$. Hearts for histological assessment were fixed for $24 \mathrm{~h}$ at room temperature in $10 \%$ neutral buffered formalin. A $2 \mathrm{~mm}$ transverse tissue slice was cut at the base-apex midpoint, processed and paraffin embedded. Sections $(5 \mu \mathrm{m})$ were stained for collagen using a modified version of Van Gieson's technique. Slides were viewed at $1 \times$ and $10 \times$ magnification under bright-field conditions and digital images acquired by a SPOT camera and software (Diagnostic Instrument Inc, Michigan, USA). Chamber and wall dimensions were measured from images using ImagePro-Plus (Media Cybernetics, version 3.0).

\section{Statistics}

Unless otherwise specified, results are presented as means \pm S.E.M. Student's two-tailed $t$-test and one- or two-way ANOVA were applied.

\section{Results}

\section{Assessment of Cre expression and function in GLUT4-Lox $^{+/+} \mathrm{Cre}^{+/-}$mice}

Cre mRNA was shown by Northern analysis to be expressed only in skeletal muscle and heart. Cre expression in heart was less than $1 \%$ of that in skeletal muscle but was consistently detected (data not shown). Probing Northern blots for Neo, which should be deleted if Cre is active, showed that
Cre is functional in the tissues in which it is expressed (Fig. 1B).

\section{Assessment for evidence of GLUT4 gene deletion}

Expression of GLUT4 was assessed using Northern and Western blotting. Both methods demonstrated that GLUT4-Lox ${ }^{+/+}$mice had reduced GLUT4 levels when compared with related wild-type controls. The mRNA transcript produced by GLUT4-Lox $^{+/+}$mice was larger than the wild-type transcript $(2 \cdot 8 \mathrm{~kb})$, and probably comprised the wild-type messenger extended through the Neo gene in an antisense direction (Fig. 1B and C). The presence of the PGK-neoR selection cassette in the GLUT4 allele caused the gene expression to be 'knocked down' (Fig. 1C; Nagy 2000). The left panel in Fig. 1C shows that in $\mathrm{Lox}^{+/+}$mice, GLUT4-Neo mRNA was transcribed at a much lower rate in all tissues tested compared with the GLUT4 expressed in the wild-type mice. The right panel in Fig. 1C underwent a longer exposure and GLUT4-Neo mRNA in $\mathrm{Lox}^{+/+}$mice is shown again. In $\mathrm{Lox}^{+/+} \mathrm{Cre}^{+/-}$animals GLUT4-Neo mRNA is further reduced in tissues which express Cre recombinase (diaphragm, heart and skeletal muscle), but not in brown adipose tissue. Western blotting confirmed that in $\mathrm{Lox}^{+/+}$mice, GLUT4 protein levels are reduced in muscle tissue $(30 \%$ of normal) (Fig. 2A) and in white (16\%) (Fig. 2B) and brown (20\%) (data not shown) adipose tissue. Other studies have also reported that this phenomenon is caused by the presence of the PGK-neoR cassette (Meyers et al. 1998, Abel et al. 1999, Nagy 2000, Rucker et al. 2000, She et al. 2000).

In heart, the presence of the PGK-neoR cassette reduced GLUT4 protein levels to approximately $15 \%$ of wild-type mice. The presence of Cre recombinase reduced GLUT4 further to almost undetectable levels (Fig. 3A). In previous models, tissue-specific upregulation of GLUT1 $(1 \cdot 5-$ to 3-fold) coincident with GLUT4 downregulation has been reported in heart but not other tissues (Katz et al. 1995, Zisman et al. 2000). In our model there was no significant GLUT1 upregulation in either skeletal muscle $\left(\mathrm{Lox}^{+/+} 96 \pm 16 \%, \mathrm{Lox}^{+/+} \mathrm{Cre}^{+/-}\right.$ $96 \pm 1 \%)$ or heart $\left(\mathrm{Lox}^{+/+} 110 \pm 13 \% \mathrm{Lox}^{+/+}\right.$ $\left.\mathrm{Cre}^{+/-} 130 \pm 20 \%\right)$ above wild-type $(n=18$ in each group). 
A
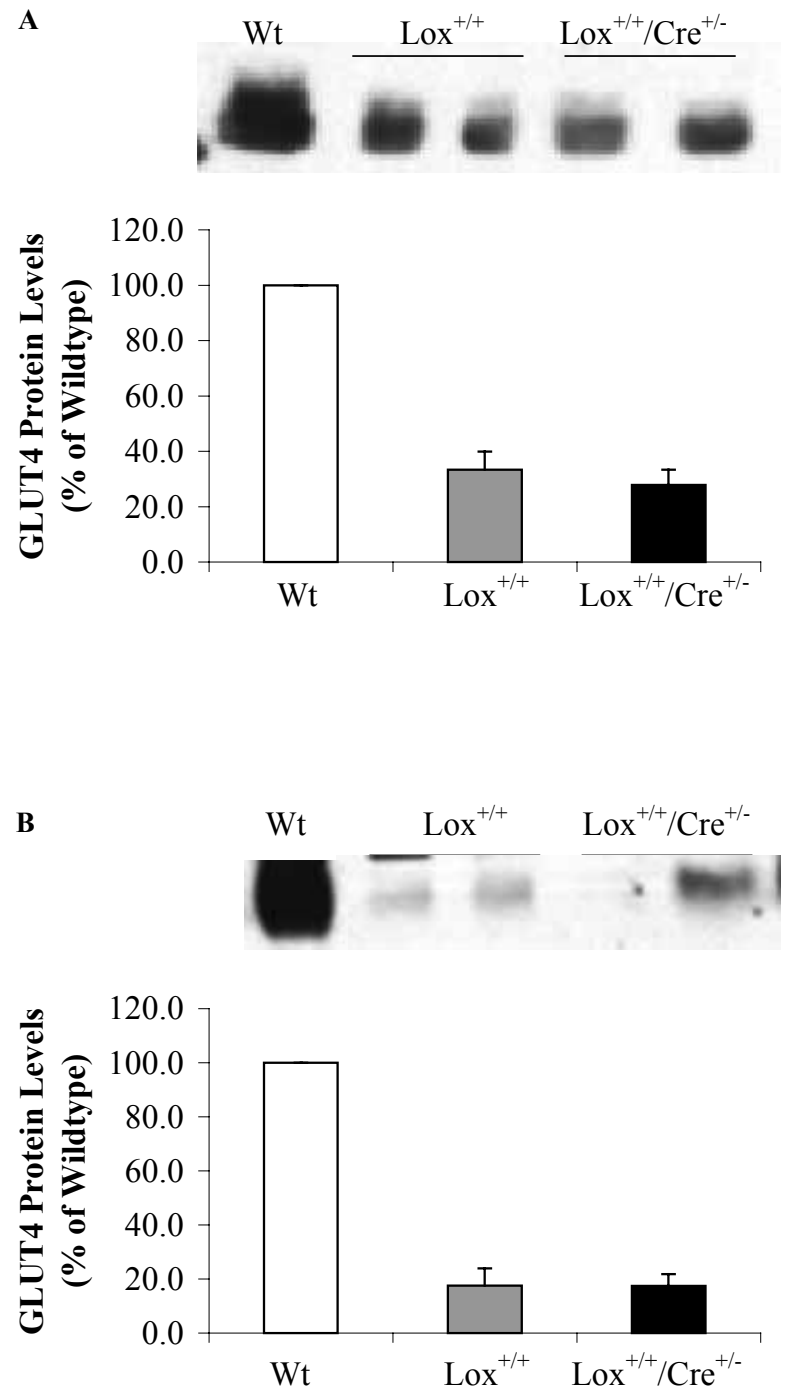

Figure 2 Western blot analysis of white quadriceps (A) and white adipose tissue $(B)$ showing that in skeletal muscle and fat, both $\mathrm{Lox}^{++} \mathrm{Cre}^{-/-}$and $\mathrm{Lox}^{+/+} \mathrm{Cre}^{+/-}$ mice have equal reduction in GLUT4 levels compared with C57BL/6 wild-type (Wt) mice. (Means \pm S.E.M., $n=6-12$ in each group.)

\section{Physiological assessment of GLUT4-deficient animals}

Fourteen-week-old male GLUT4-deficient mice were compared with age-matched wild-type C57BL/6 control mice. The GLUT4-deficient animals had normal body weights $(28.6 \pm 0.9 \mathrm{~g}$, $\mathrm{Lox}^{+/+} 29 \cdot 1 \pm 1 \cdot 4 \mathrm{~g}$ and $\mathrm{Lox}^{++} \mathrm{Cre}^{+/-} 28 \cdot 2 \pm$ $0.9 \mathrm{~g})$. Fasting glucose was not elevated but insulin levels were double in the GLUT4-deficient animals $(P=0 \cdot 003)$ indicating insulin resistance (Table 1).
$\mathbf{A}$
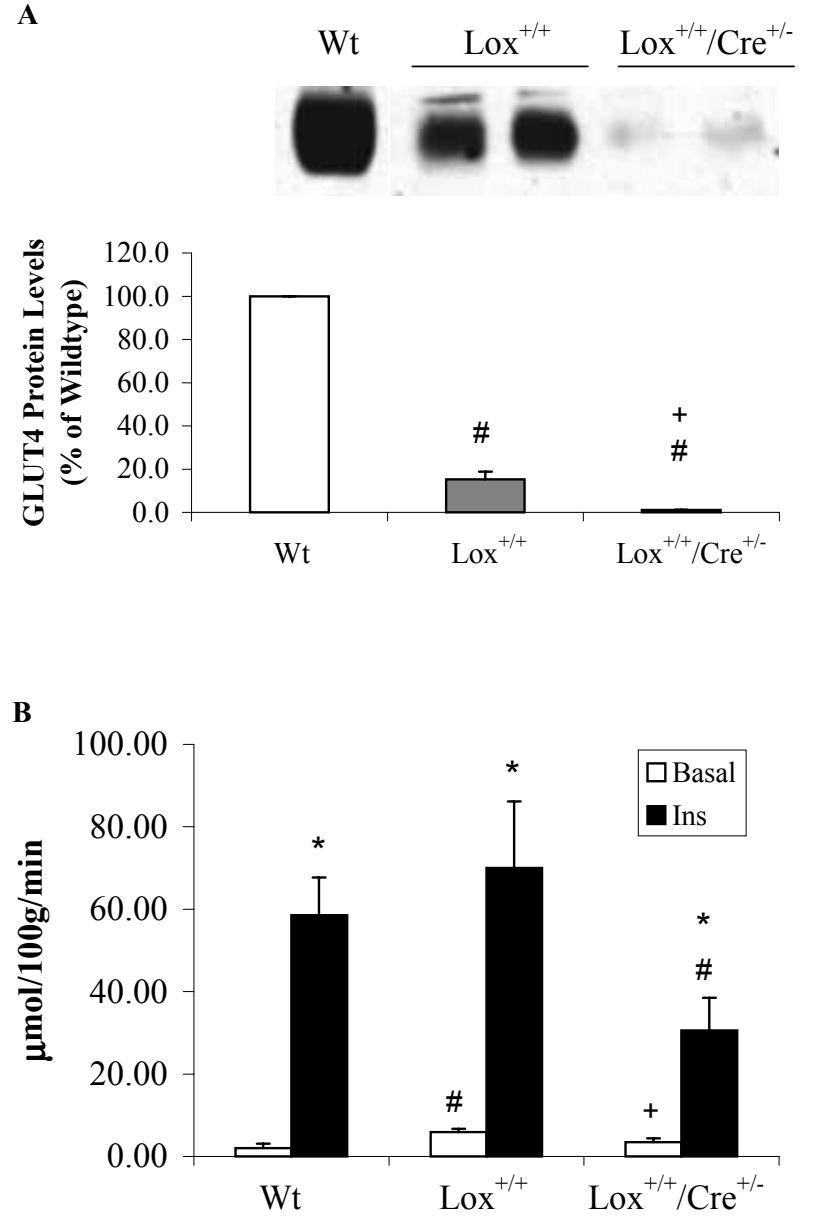

Figure 3 (A) Western blots of heart tissue. Lox ${ }^{+/+}$mice had profoundly reduced GLUT4 levels, to approximately $15 \%$ of normal. Cre expression caused a further reduction in GLUT4 to very low levels $(n=6-12$ in each group). (B) Basal ( $n=3-4)$ and insulin-stimulated ( $n=6-9)$ 2-deoxyglucose uptake in heart. ${ }^{*} P<0.05$ vs basal, ${ }^{\#} P<0.05$ vs wild-type (Wt), ${ }^{+} P<0.05$ vs Lox $^{+/+}$. (Means \pm S.E.M.)

During the hyperinsulinaemic clamp, plasma glucose levels were higher in the GLUT4deficient mice compared with wild-type but insulin levels were not different in the three groups (Table 1).

Whole-body glucose kinetics showed that the basal rate of glucose uptake and metabolic clearance rate (MCR) of glucose were not different in the three groups of mice (Table 1). However, in the insulin-stimulated state, MCR was lower in the $\mathrm{Lox}^{+/+}$and $\mathrm{Lox}^{+/+} \mathrm{Cre}^{+/-}$mice (Table 1) indicating a defect in insulin-mediated glucose uptake in GLUT4-deficient mice. 
Table 1 Glucose, insulin, rate of glucose disappearance (Rd) and metabolic clearance rate (MCR) in male wild-type (C57/BL/6J), GLUT4-Lox ${ }^{+/+}$and Lox $^{+/} \mathrm{Cre}^{+/-}$mice during glucose turnover studies. Means \pm S.E.M.

\begin{tabular}{|c|c|c|c|c|c|c|}
\hline & \multicolumn{3}{|c|}{ Basal $(n=4)$} & \multicolumn{3}{|c|}{ Clamp $(n=6-9)$} \\
\hline & Wild-type & $\operatorname{Lox}^{+/+}$ & $\mathrm{Lox}^{+/+} \mathrm{Cre}^{+/-}$ & Wild-type & $\operatorname{Lox}^{+/+}$ & $\mathrm{Lox}^{+/+} \mathrm{Cre}^{+/-}$ \\
\hline \multicolumn{7}{|l|}{ Parameter } \\
\hline Glucose (mmol/l) & $7 \cdot 1 \pm 0.5$ & $7 \cdot 6 \pm 0.4$ & $7 \cdot 6 \pm 1 \cdot 3$ & $6 \cdot 1 \pm 0 \cdot 6$ & $10 \cdot 1 \pm 0.9^{*}$ & $13 \cdot 1 \pm 1 \cdot 0^{*}$ \\
\hline Insulin $(\mu \mathrm{U} / \mathrm{ml})$ & $19 \cdot 1 \pm 3 \cdot 2$ & $51 \cdot 6 \pm 4 \cdot 6^{*}$ & $64.5 \pm 14.4^{*}$ & $255 \pm 39$ & $215 \pm 47$ & $201 \pm 30$ \\
\hline $\mathrm{Rd}(\mu \mathrm{mol} / \mathrm{kg}$ per $\mathrm{min})$ & $64 \cdot 7 \pm 8 \cdot 3$ & $54 \cdot 8 \pm 4 \cdot 0$ & $63 \cdot 9 \pm 14 \cdot 7$ & $146 \pm 18^{\#}$ & $119 \pm 15^{\#}$ & $122 \pm 14^{\#}$ \\
\hline $\mathrm{MCR}(\mathrm{ml} / \mathrm{kg}$ per $\mathrm{min})$ & $9 \cdot 1 \pm 0.7$ & $7 \cdot 4 \pm 0.8$ & $8 \cdot 1 \pm 1 \cdot 1$ & $25 \cdot 1 \pm 4 \cdot 1^{\#}$ & $13 \cdot 0 \pm 1 \cdot 8^{\star \#}$ & $11 \cdot 4 \pm 0 \cdot 8^{\star \#}$ \\
\hline
\end{tabular}

${ }^{*} P<0.05$ vs wild-type; ${ }^{\#} P<0.05$ vs respective basal.

Glucose uptake in muscle and white and brown adipose tissue is shown in Table 2. Basal glucose uptake tended to be higher in $\mathrm{Lox}^{+/+}$and $\mathrm{Lox}^{+/+} \mathrm{Cre}^{+/-}$possibly in response to the higher fasting insulin in these animals. When insulin levels were equalised at a physiological hyperinsulinaemic level during the clamp, white quadriceps and white and brown adipose tissue showed reduced glucose uptake in mice expressing reduced GLUT4 levels (Table 2).

In the heart, basal glucose uptake was higher in GLUT4-Lox $^{+/+}$mice compared with wild-type, again reflecting the fasting hyperinsulinaemia in these animals. The threshold effect of GLUT4 on insulin-stimulated glucose uptake is clearly demonstrated in the heart. It can be seen that $15 \%$ of GLUT4 is sufficient to allow normal insulinstimulated glucose uptake (Fig. 3B). However, the almost complete absence of GLUT4 in the $\mathrm{Lox}^{+/+} / \mathrm{Cre}^{+/-}$mice reduced insulin-stimulated glucose uptake.

Table 2 2-Deoxy-glucose uptake $(\mu \mathrm{mol} / 100 \mathrm{~g} / \mathrm{min})$ in white quadriceps (WQ), white adipose tissue (WAT) and brown adipose tissue (BAT). Means \pm S.E.M.

\begin{tabular}{|c|c|c|c|}
\hline & Wild-type & $\operatorname{Lox}^{+/+}$ & $\mathrm{Lox}^{+/+} \mathrm{Cre}^{+/-}$ \\
\hline $\begin{array}{l}\text { Basal }(n=3-4) \\
\text { WQ } \\
\text { WAT } \\
\text { BAT }\end{array}$ & $\begin{array}{l}0.6 \pm 0.1 \\
0.2 \pm 0.1 \\
1.0 \pm 0.4\end{array}$ & $\begin{array}{l}1 \cdot 2 \pm 0 \cdot 3 \\
0.5 \pm 0 \cdot 2 \\
2 \cdot 3 \pm 0 \cdot 7\end{array}$ & $\begin{array}{l}1 \cdot 4 \pm 0 \cdot 2^{*} \\
1 \cdot 2 \pm 0 \cdot 1^{\text {*\# }} \\
4.5 \pm 1 \cdot 4^{*}\end{array}$ \\
\hline $\begin{array}{l}\text { Clamp }(n=6-9) \\
\text { WQ } \\
\text { WAT } \\
\text { BAT }\end{array}$ & $\begin{array}{r}4.8 \pm 0.5 \\
3.1 \pm 0.6 \\
37 \cdot 3 \pm 7.9\end{array}$ & $\begin{array}{l}4 \cdot 7 \pm 0 \cdot 8 \\
1.4 \pm 0 \cdot 4^{*} \\
3.5 \pm 0.8^{*}\end{array}$ & $\begin{array}{l}2 \cdot 6 \pm 0 \cdot 4^{\star \#} \\
2 \cdot 3 \pm 0 \cdot 5 \\
5 \cdot 9 \pm 2 \cdot 4^{*}\end{array}$ \\
\hline
\end{tabular}

${ }^{\star} P<0.05$ vs wild-type; ${ }^{*} P<0.05$ vs Lox ${ }^{+/+}$.

\section{Blood pressure measurement}

Blood pressure was measured in age- and sex-matched $\mathrm{Lox}^{+/+}$(that have no hypertrophy) $(n=11)$ and in $\mathrm{Lox}^{+/+} \mathrm{Cre}^{+/-}$mice (with cardiac hypertrophy) $(n=9)$. Table 3 shows that cardiac hypertrophy was not associated with elevated mean arterial pressure. The values obtained for mean arterial pressure were comparable with those previously reported in anaesthetised wild-type C57BL6 mice at similar heart rate (Nemoto et al. 2002).

\section{Threshold effects of GLUT4 deficiency on cardiac morphology}

CWIs for the three animal groups (wild-type, $\mathrm{Lox}^{+/+}$and $\mathrm{Lox}^{+/+} \mathrm{Cre}^{+/-}$) are shown in Fig. 4A. In Lox ${ }^{+/+}$mice, a modest $15 \%$ increase in CWI is seen in association with the $85 \%$ reduction in GLUT4 level. In the $\mathrm{Lox}^{+/+} \mathrm{Cre}^{+/-}$mice there is a dramatic hypertrophy (approximately $80 \%$ increase in CWI) associated with a loss of $99 \%$ of GLUT4 protein. There was no difference in heart to body weight ratio between male and female animals and the data for these mice were pooled.

To explore the relationship between GLUT4 expression and CWI further, paired data were analysed. The plot of cardiac GLUT4 levels and GWI in $\mathrm{Lox}^{+/+}$and $\mathrm{Lox}^{+/+} \mathrm{Cre}^{+/-}$mice (Fig 4B) shows that there is a threshold effect in this relationship. Suppression of GLUT4 protein levels in the heart to below $5 \%$ of wild-type levels is linked with a grossly hypertrophic phenotype. It is evident that there is no overlap between the $\mathrm{Lox}^{+/+}$and $\mathrm{Lox}^{+/+} \mathrm{Cre}^{+/-}$distributions of these two variables. 
Table 3 Age, heart weight to body weight ratio (HW/BW), maximal heart rate (HRmax) and mean arterial pressure measured maximal heart rate (MAP@HRmax) in Lox ${ }^{++}$ and $\mathrm{Lox}^{+/+} \mathrm{Cre}^{+/-}$mice. Means \pm S.E.M.

\begin{tabular}{|c|c|c|c|c|}
\hline & $\begin{array}{l}\text { Age } \\
\text { (weeks) }\end{array}$ & HW/BW & $\begin{array}{l}\underset{(b p m)}{\operatorname{HRmax}} \\
\text { (bpm) }\end{array}$ & $\begin{array}{l}\text { MAP@HRmax } \\
(\mathrm{mmHg})\end{array}$ \\
\hline \multicolumn{5}{|l|}{ Mice } \\
\hline $\operatorname{Lox}^{+/+}(n=11)$ & $29 \cdot 5 \pm 6 \cdot 1$ & $5 \cdot 5 \pm 0.2$ & $390 \pm 25$ & $86 \cdot 7 \pm 6 \cdot 4$ \\
\hline $\mathrm{Lox}^{+/+} \mathrm{Cre}^{+/-}(n=9)$ & $33 \cdot 0 \pm 8 \cdot 7$ & $8 \cdot 2 \pm 0.3^{\star *}$ & $352 \pm 27$ & $74 \cdot 8 \pm 5 \cdot 2$ \\
\hline
\end{tabular}

Histological evaluation of Van Gieson-stained sections showed that, compared with the wild-type and $\mathrm{Lox}^{+/+}$mice, the hypertrophic phenotype of the hearts from the $\mathrm{Lox}^{+/+} \mathrm{Cre}^{+/-}$mice was accompanied by a marked interstitial fibrosis and fibroblast hyperplasia. Analysis of the chamber

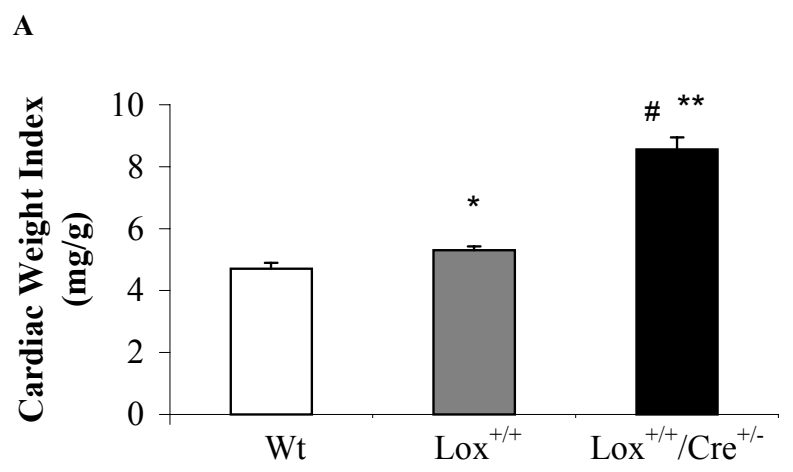

B

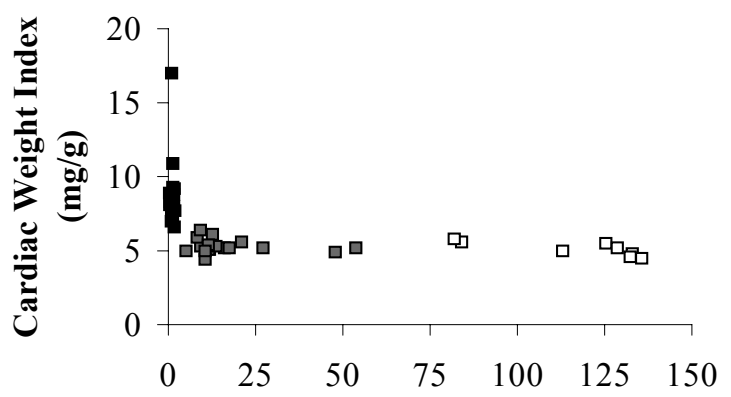

GLUT4 Protein Levels (arbitrary units)

Figure 4 (A) Percent heart to body weight ratio in wild-type (Wt), $\mathrm{Lox}^{+/+}$and $\mathrm{Lox}^{+/+} \mathrm{Cre}^{+/}$mice. ${ }^{*} P<0.05$ vs wild-type, ${ }^{* \star} P<0.001$ vs wild-type, ${ }^{\#} P<0.001$ vs $L^{\circ} x^{+/+}$.

(B) Plot of GLUT4 levels expressed as arbitrary units vs $\mathrm{CWI}$ in wild-type (open squares), $\mathrm{Lox}^{+/+}$(grey squares) and $\mathrm{Lox}^{+/+} \mathrm{Cre}^{+/-}$(black squares). (Means \pm S.E.M.) $(n=8-16)$. dimensions demonstrated that there was a $65 \%$ increase in both the left and right ventricular wall thickness of the $\mathrm{Lox}^{+/+} \mathrm{Cre}^{+/-}$mice $(P<0 \cdot 001)$, with a proportional increase in the left ventricular chamber (Fig. 5). These results indicate that the threshold effect of GLUT4 reduction below $5 \%$ of wild-type control level is associated with marked hypertrophic and fibrotic remodelling of the myocardium.

\section{Discussion}

Diabetes, a condition that is estimated to affect over 100 million people worldwide and whose prevalence is increasing rapidly, is associated with cardiac abnormalities independently of associated hypertension and probably due to the metabolic derangement present. Both functional (Shapiro et al. 1981) and structural (van Hoeven \& Factor 1990) abnormalities have been described. Although there may be several different mechanisms for these diabetes-related cardiac abnormalities, one possibility is a reduction in glucose availability secondarily to a marked reduction in the insulinresponsive glucose transporter (GLUT4) expression (Garvey et al. 1993). Consistent with the deficiency of energy substrates as the cause of cardiac abnormalities, is the fact that inhibition of free fatty acid oxidation, the heart's major energy source, results in cardiac enlargement (Litwin et al. 1990b).

In this study we have investigated the relationship between GLUT4 transporter expression, glucose uptake and cardiac hypertrophy in a novel murine model produced using the CreLoxP system. In heart, where there was a difference in GLUT4 levels between the GLUT4-Lox ${ }^{+/+}$and GLUT4$\mathrm{Lox}^{+/+} \mathrm{Cre}^{+/-}$mice, insulin-stimulated glucose uptake was normal in mice with $15 \%$ of wild-type GLUT4 levels, but was reduced in mice with near 


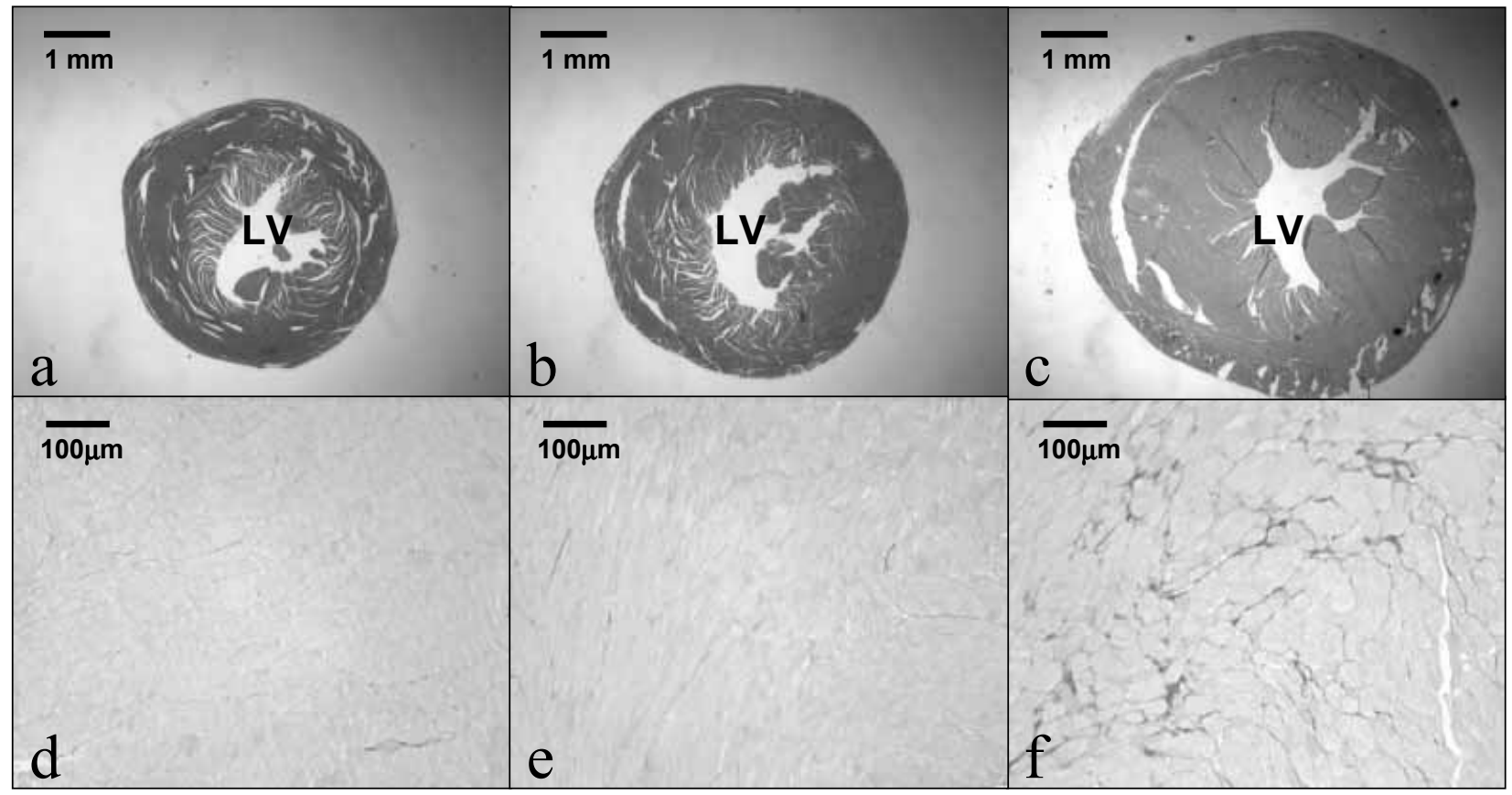

Figure 5 Collagen-specific Van Gieson-stained transverse sections of ventricles in wild-type (a), Lox ${ }^{+/+}$(b) and $\mathrm{Lox}^{+/+} \mathrm{Cre}^{+/-}$(c) mice. Histology showing that excess fibrosis in ventricular tissues is present only in hearts from $\mathrm{Lox}^{+/+} \mathrm{Cre}^{+/-}$mice (f), but not in wild-type (d) or Lox ${ }^{+/+}(\mathrm{e})$ animals. LV, left ventricle.

complete absence of this transporter. These data suggest that in active cardiac muscle, there is a threshold above which GLUT4 deficiency does not impair insulin-stimulated glucose uptake. It has been reported that in the global knockout model, GLUT4-null hearts have the same rate of 2-deoxyglucose-6-phosphate accumulation as controls when measured in the isolated perfused state (Stenbit et al. 2000). In agreement with this, we could not detect any significant difference in basal glucose uptake in our mice with complete GLUT4 deficiency. A reduction in glucose uptake appeared in our GLUT4-null mice when the hearts were stimulated with insulin in vivo (Fig. 3B).

It is interesting that in the $\mathrm{Lox}^{+/+}$mice that respond normally to insulin, basal glucose uptake was elevated compared with wild-type, possibly reflecting a normal response to the hyperinsulinaemia present in these animals (Table 1). In contrast, in $\mathrm{Lox}^{+/+} \mathrm{Cre}^{+/-}$mice that have no GLUT4 expression, basal glucose transport was not elevated. The normal cardiac basal glucose uptake in the $\mathrm{Lox}^{+/+} \mathrm{Cre}^{+/-}$animals is consistent with the normal levels of GLUT1 detected. This is different to the heart-specific GLUT4 knockout model in which it was shown that a 3-fold increase in basal glucose uptake was associated with a 3-fold increase in GLUT1 expression (Abel et al. 1999). Why our model does not show enhanced basal glucose uptake and increased expression of GLUT1 is not clear. A possible explanation is the different genetic background of the animals.

It is unlikely that anaesthesia influenced the relative findings of glucose uptake and insulin action in this study. The effects of anaesthesia on basal and insulin-stimulated glucose uptake have been investigated in rats. It was found that anaesthesia reduced insulin-stimulated glucose uptake in soleus and more modestly in plantaris, red quadriceps and red gastrocnemius but it did not reduce uptake in white quadriceps or in white adipose tissue (James et al. 1986). In addition any effects of anaesthesia would be the same in all three groups studied.

The threshold effects of GLUT4 levels are clearly demonstrated in the effects of GLUT4 deficiency on cardiac size. Previous models of complete GLUT4 deficiency, both global (Stenbit et al. 2000) and cardiac-specific (Abel et al. 1999), have demonstrated cardiac hypertrophy. In global knockout mice with no GLUT4 expression in any tissue, there was a $2 \cdot 5$-fold increase in cardiac size 
with myocyte hypertrophy in all chambers (Katz et al. 1995). These mice, like those described in this report, were normotensive (Stenbit et al. 2000). In heart-specific GLUT4-deficient mice, the hypertrophy was more modest (1-4-fold increase) (Abel et al. 1999), leading the authors to speculate that the metabolic abnormalities present in mice with more widespread deficiency of GLUT4 might contribute to cardiac enlargement (Abel et al. 1999). However, our data do not support such a conclusion. Lox ${ }^{+/+}$ and $\mathrm{Lox}^{+/+} \mathrm{Cre}^{+/-}$animals had similar deficiency of GLUT4 levels in peripheral tissues with a consequent similar level of hyperinsulinaemia and a similar reduction in MCR compared with wild-type mice (Table 1). They had, however, a very different degree of cardiac enlargement, which appears to be related to the severity of GLUT4 deficiency in the heart. We show here that to induce marked cardiac hypertrophy, GLUT4 levels need to be reduced to less than $5 \%$ of normal (Fig. 3). In this situation, the cardiac hypertrophy is associated with a marked increase in interstitial collagen.

It is well known that the presence of the PGK-neoR cassette in a gene may create a 'knockdown' allele with low and variable levels of transcription (Nagy 2000). Several groups have reported this phenomenon. Thus, She et al. (2000), studying the role of phosphoenolpyruvate carboxykinase (PEPGK) in hepatic energy metabolism, produced both PEPGK ${ }^{\text {Lox lox }}$ and

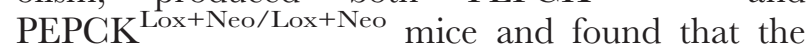
presence of the Neo cassette between exons 3 and 4 reduced PEPCK expression in both liver and kidney to about $10-20 \%$ of normal. In the GLUT4-Lox mice used to produce cardiac- (Abel et al. 1999) and muscle- (Zisman et al. 2000) specific GLUT4 deletion, GLUT4 expression in white adipose tissue was reduced by up to $50 \%$. It is not clear why in this model the Neo interfered with GLUT4 expression in fat but not in muscle as it did in our model. We have also demonstrated that Gre recombinase further reduces GLUT4 mRNA levels in the tissues it is expressed in (Fig. 1C). Despite the fact that there appears to be little difference in GLUT4 mRNA levels in these tissues (Fig. 1G), GLUT4 protein levels were further reduced in heart but not in other muscle tissues. This suggests that GLUT4 protein turnover may be faster in heart.

In conclusion, we have established that in cardiac muscle, GLUT4 levels need to be profoundly reduced to impair insulin-stimulated glucose uptake when measured at physiological insulin levels in anaesthetised mice. Additionally we have demonstrated that gross cardiac enlargement will be evident only when GLUT4 levels are reduced to below $95 \%$ of normal values.

\section{Acknowledgements}

This work was supported by NH\&MRC project grants Nos 923210, 970377 and 114167 and from a grant-in-aid from Diabetes Australia. A A D was supported by doctoral scholarships from the Roche Research foundation (Fli7 stm 98-120) and the Swiss National Science Foundation. We wish to express our thanks to Dr Gennaro Rosella, Mrs Susan Franceschini, Mr David Kahn and Ms Jenny Davis for technical assistance. The assistance of Dr Shintaro Nemoto in optimising blood pressure recording techniques is gratefully acknowledged.

\section{References}

Abel ED, Kaulbach HC, Tian R, Hopkins JC, Duffy J, Doetschman T, Minnemann T, Boers ME, Hadro E, Oberste-Berghaus C et al. 1999 Cardiac hypertrophy with preserved contractile function after selective deletion of GLUT4 from the heart. Fournal of Clinical Investigation 104 1703-1714.

Brennan KJ \& Hardeman EC 1993 Quantitative analysis of the human alpha-skeletal actin gene in transgenic mice. Fournal of Biological Chemistry 268 719-725.

Bressler R \& Goldman S 1993 A role of fatty acid oxidation in cardiac hypertrophy. Cardioscience 4 133-142.

Garvey WT, Hardin D, Juhaszova M \& Dominguez JH 1993 Effects of diabetes on myocardial glucose transport system in rats: implications for diabetic cardiomyopathy. American Fournal of Physiology 264 H837-H844.

Gertz EW, WisneskiJA, Stanley WC \& Neese RA 1988 Myocardial substrate utilization during exercise in humans. Dual carbon-labeled carbohydrate isotope experiments. Fournal of Clinical Investigation 82 2017-2025.

Hirayama H, Sugano M, Abe N, Yonemochi H \& Makino N 2000 Determination of left ventricular mass by echocardiography in normotensive diabetic patients. Fapanese Circulation Fournal 64 921-924.

Hogan B, Constantini F \& Lacy E 1986 Manipulating the Mouse Embryo: a Laboratory Manual. Cold Spring Harbor, NY: Cold Spring Harbor Laboratory Press.

James DE, Burleigh KM, Storlien LH, Bennett SP \& Kraegen EW 1986 Heterogeneity of insulin action in muscle: influence of blood flow. American Fournal of Physiology 251 E422-E430.

Katz EB, Stenbit AE, Hatton K, DePinho R \& Charron MJ 1995 Cardiac and adipose tissue abnormalities but not diabetes in mice deficient in GLUT4 [see comments]. Nature 377 151-155.

Kelada AS, Macaulay SL \& Proietto J 1992 Cyclic AMP acutely stimulates translocation of the major insulin-regulatable glucose transporter GLUT4. Fournal of Biological Chemistry 267 7021-7025. 
Kraegen EW, Sowden JA, Halstead MB, Clark PW, Rodnick KJ, Chisholm DJ \& James DE 1993 Glucose transporters and in vivo glucose uptake in skeletal and cardiac muscle: fasting, insulin stimulation and immunoisolation studies of GLUT-1 and GLUT-4. Biochemical fournal 295 287-293.

Lieschke GJ, Grail D, Hodgson G, Metcalf D, Stanley E, Cheers C, Fowler KJ, Basu S, Zhan YF \& Dunn AR 1994 Mice lacking granulocyte colony-stimulating factor have chronic neutropenia, granulocyte and macrophage progenitor cell deficiency, and impaired neutrophil mobilization. Blood 84 27-35.

Litwin SE, Raya TE, Anderson PG, Daugherty S \& Goldman S 1990 a Abnormal cardiac function in the streptozotocin-diabetic rat. Changes in active and passive properties of the left ventricle. Fournal of Clinical Investigation 86 481-488.

Litwin SE, Raya TE, Gay RG, Bedotto JB, Bahl JJ, Anderson PG, Goldman S \& Bressler R 1990b Chronic inhibition of fatty acid oxidation: new model of diastolic dysfunction. American Fournal of Physiology 258 H51-H56.

Meyers EN, Lewandoski M \& Martin GR 1998 An Fgf8 mutant allelic series generated by Cre- and Flp-mediated recombination. Nature Genetics 18 136-141.

Miniou P, Tiziano D, Frugier T, Roblot N, Le Meur M \& Melki J 1999 Gene targeting restricted to mouse striated muscle lineage. Nucleic Acids Research 27 e27 i-iv.

Muscat GE \& Kedes L 1987 Multiple 5'-flanking regions of the human alpha-skeletal actin gene synergistically modulate muscle-specific expression. Molecular and Cellular Biology 7 4089-4099.

Nagy A 2000 Cre recombinase: the universal reagent for genome tailoring. Genesis 26 99-109.

Nemoto S, DeFreitas G \& Carabello BA 2003 Cardiac catheterization technique in a closed-chest murine model. Contemporary Topics $\mathbf{4 2} 28-32$.

Nielsen FS, Ali S, Rossing P, Bang LE, Svendsen TL, Gall MA, Smidt UM, Kastrup J \& Parving HH 1997 Left ventricular hypertrophy in non-insulin-dependent diabetic patients with and without diabetic nephropathy. Diabetic Medicine 14 538-546.

Rucker EB III, Dierisseau P, Wagner KU, Garrett L, Wynshaw-Boris A, Flaws JA \& Hennighausen L 2000 Bcl-x and Bax regulate mouse primordial germ cell survival and apoptosis during embryogenesis. Molecular Endocrinology 14 1038-1052.
Sambrook J, Fritsch EF \& Maniatis T 1989 Molecular Cloning: a Laboratory Manual. Cold Spring Harbor, NY: Cold Spring Harbor Laboratory Press.

Shapiro LM, Howat AP \& Calter MM 1981 Left ventricular function in diabetes mellitus. I: Methodology, and prevalence and spectrum of abnormalities. British Heart Fournal 45 122-128.

She P, Shiota M, Shelton KD, Chalkley R, Postic C \& Magnuson MA 2000 Phosphoenolpyruvate carboxykinase is necessary for the integration of hepatic energy metabolism. Molecular and Cellular Biology 20 6508-6517.

Slot JW, Geuze HJ, Gigengack S, James DE \& Lienhard GE 1991 Translocation of the glucose transporter GLUT4 in cardiac myocytes of the rat. PNAS 88 7815-7819.

Sprafka JM, Burke GL, Folsom AR, McGovern PG \& Hahn LP 1991 Trends in prevalence of diabetes mellitus in patients with myocardial infarction and effect of diabetes on survival. The Minnesota Heart Survey. Diabetes Care 14 537-543.

Stenbit AE, Katz EB, Chatham JC, Geenen DL, Factor SM, Weiss RG, Tsao TS, Malhotra A, Chacko VO, Ocampo C et al. 2000 Preservation of glucose metabolism in hypertrophic GLUT4-null hearts. American Fournal of Physiology: Heart and Circulatory Physiology 279 H313-H318.

van Hoeven KH \& Factor SM 1990 A comparison of the pathological spectrum of hypertensive, diabetic, and hypertensive-diabetic heart disease. Circulation 82 848-855.

Veroni M, Proietto J \& Larkins R 1991 Evolution of insulin resistance in New Zealand obese mice. Diabetes 40 1480-1487.

Xu X, Li C, Garrett-Beal L, Larson D, Wynshaw-Boris A \& Deng CX 2001 Direct removal in the mouse of a floxed neo gene from a three-loxp conditional knockout allele by two novel approaches. Genesis 30 1-6.

Zisman A, Peroni OD, Abel ED, Michael MD, Mauvais-Jarvis F, Lowell BB, Wojtaszewski JF, Hirshman M, Virkamaki A, Goodyear LJ et al. 2000 Targeted disruption of the glucose transporter 4 selectively in muscle causes insulin resistance and glucose intolerance. Nature Medicine 6 924-928.

Received 15 August 2003

Accepted 1 September 2003 